\title{
Dayside and nightside contributions to cross-polar cap potential variations: the 20 March 2001 ICME case
}

\author{
Y. L. Andalsvik ${ }^{1}$, P. E. Sandholt ${ }^{1}$, and C. J. Farrugia ${ }^{2}$ \\ ${ }^{1}$ Department of Physics, University of Oslo, Oslo, Norway \\ ${ }^{2}$ Space Science Center, University of New Hampshire, Durham, USA
}

Received: 18 August 2011 - Revised: 8 November 2011 - Accepted: 12 November 2011 - Published: 29 November 2011

\begin{abstract}
We investigate the association between temporalspatial structure of polar cap convection and auroral electrojet intensifications during a 5-h-long interval of strong forcing of the magnetosphere by an ICME/Magnetic cloud on 20 March 2001. We use data from coordinated ground-satellite observations in the 15:00-20:00 MLT sector. We take advantage of the good latitudinal coverage in the polar cap and in the auroral zone of the IMAGE chain of ground magnetometers in Svalbard - Scandinavia - Russia and the stable magnetic field conditions in ICMEs. The electrojet events are characterized by a sequence of 10 min-long AL excursions to $-1000 /-1500 \mathrm{nT}$ followed by poleward expansions and auroral streamers. These events are superimposed on a high disturbance level when the AL index remains around $-500 \mathrm{nT}$ for several hours. These signatures are different from those appearing in classical substorms, most notably the absence of a complete recovery phase when AL usually reaches above $-100 \mathrm{nT}$. We concentrate on polar cap convection in both hemispheres (DMSP F13 data) in relation to the ICME $B_{\mathrm{y}}$ conditions, electrojet intensifications, and the global UV auroral configuration obtained from the IMAGE spacecraft. The temporal evolution of convection properties such as the cross-polar cap potential (CPCP) drop and flow channels at the dawn/dusk polar cap (PC) boundaries around the time of the electrojet events are investigated. This approach allows us to distinguish between dayside (magnetopause reconnection) and nightside (magnetotail reconnection) sources of the PC convection events within the context of the expanding-contracting model of high-latitude convection in the Dungey cycle. Inter-hemispheric symmetries/asymmetries in the presence of newly-discovered convection channels at the dawn or dusk side PC boundaries are determined.
\end{abstract}

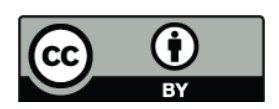

Correspondence to: Y. L. Andalsvik (y.l.andalsvik@fys.uio.no)
Keywords. Ionosphere (Plasma convection) - Magnetospheric physics (Auroral phenomena; Polar cap phenomena)

\section{Introduction}

In this study we extend previous investigations of polar cap convection and specific polar cap (PC) flow channels appearing during intervals of strong and stable forcing of the magnetosphere associated with Earth passage of interplanetary CMEs (Burlaga et al., 1981). A PC flow channel is defined as a latitudinally restricted (few $100 \mathrm{~km}$ ) regime of enhanced $\left(>1 \mathrm{~km} \mathrm{~s}^{-1}\right)$ antisunward convection. Here we shall focus on the condition of strongly south directed magnetic field $\left(B_{\mathrm{z}}=-15 \mathrm{nT} ; B_{\mathrm{y}}=0\right)$ in the ICME of 20 March 2001 during a 5-h-long interval when the ICME magnetic field rotated slowly from a south-westerly $\left(B_{\mathrm{z}}<0 ; B_{\mathrm{y}}<0\right)$ to a southeasterly orientation $\left(B_{\mathrm{z}}<0 ; B_{\mathrm{y}}>0\right)$. This extension consists of a data-based investigation of the temporal behaviour of the cross-polar cap potential (CPCP) as the dayside and nightside sources of the plasma convection in the ionosphere vary.

Figure 1 shows a schematic illustration of a combined high-latitude (HBL) - low-latitude boundary layer (LLBL) - tail plasma sheet model of the multi-stage evolution of Dungey cell plasma convection, emphasizing the dayside and nightside sources of plasma flows in the polar cap ionosphere along the periphery of the polar cap. Basic components of the model are (i) symmetric $\left(B_{\mathrm{y}}=0\right)$ ionospheric convection cells/channels, (ii) westward electrojet (WEJ) currents with (iii) the associated poleward boundary intensifications (PBIs) in the aurora at the nightside polar cap boundary, (iv) fieldaligned currents (R1, R2 and polar cap FACs), (v) magnetospheric currents (cross-tail current $J_{\mathrm{CT}}$ and partial ring current $J_{\mathrm{PRC}}$ ), (vi) bursty bulk flows (BBFs) in the tail plasma sheet, (vii) currents flowing in the HBL (solar wind dynamo

Published by Copernicus Publications on behalf of the European Geosciences Union. 


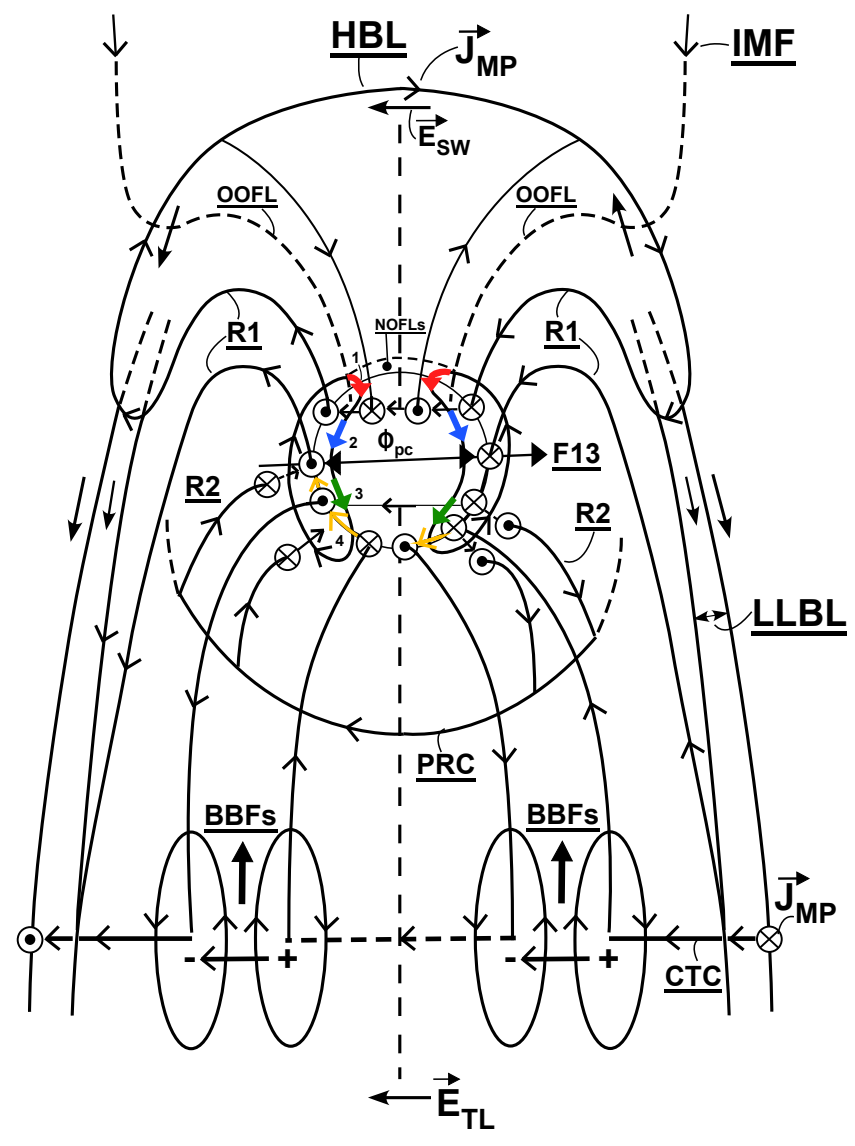

Fig. 1. Sketch of central features of multi - stage plasma convection and associated FACs of the magnetosphere-ionosphere system with emphasis on the periphery of the polar cap (see text for details). Flow channels/stages FC 1, FC 2, and FC 3, and the westward electrojet current are marked by red, blue, green, and yellow arrows, respectively.

region) and (viii) in the LLBL on the flanks of the magnetosphere.

In line with previous studies we include the temporal evolution and thus we distinguish between flow channels appearing in conjunction with newly open magnetic field lines (LLBL/cusp-type precipitation and poleward-moving auroral forms) and magnetic field lines in a later stage of evolution (old open field lines) with "feet" in polar rain precipitation (marked NOFLs and OOFLs, respectively). We refer to the ionospheric flow channels, which arise from the closure of the associated field-aligned currents via ionospheric Pedersen currents, as FC 1 and FC 2, respectively.

Related to this we note that Southwood (1987) predicted channels of pulsed flows on the flanks of the polar cap as a result of flux transfer events (FTEs) and concluded that "only near the periphery of the polar cap would the timedependence be very evident." Such channels of pulsed antisunward flows on old open field lines (polar rain precipitation) were documented by Sandholt and Farrugia (2009) and
Sandholt et al. (2010). Our aim here is to study the possible contribution of these flows to the CPCP fluctuations as measured by satellites in polar orbit or by ground-based radars. At the same time we aim at distinguishing between the dayside and nightside sources of CPCP fluctuations.

Figure 1 marks four consecutive stages in the evolution of the Dungey (1961) convection cycle. Stages 1 and 2, representing the first 20-25 min in the cycle, are accompanied by flow channels FC 1 (red) and FC 2 (blue), respectively. As noted, FC 2 is associated with the ionospheric Pedersen current closure of the dayside current system consisting of the following elements: R1 FAC - LLBL current - magnetopause current - polar cap FAC. The ionospheric Pedersen current closure gives rise to the FC 2 flow channels located near the polar cap boundary in the prenoon and/or postnoon sectors (Sandholt and Farrugia, 2009). As illustrated by the present case, flow channel FC 2 is strong on the dawn side in the Northern Hemisphere during IMF $B_{\mathrm{y}}>0$ conditions (see also Sandholt and Farrugia, 2009). For $B_{\mathrm{y}}<0$ the reverse is the case. Concerning the IMF clock angle dependence of FACs illustrated in Fig. 1 we refer to Papitashvili et al. (2002).

In Fig. 1, stage 3 of the Dungey cycle is represented by flow channel FC 3 (green) located in the pre- and postmidnight sectors (see Wang et al., 2010). As we shall argue below, channel FC 3 may be driven by processes in the tail lobe and/or tail plasma sheet. In this connection we note that the $\boldsymbol{E}$-field at the tail lobe-plasma sheet interface $\left(\boldsymbol{E}_{\mathrm{TL}}\right)$ is an important parameter for initiating plasma sheet thinning and subsequent magnetotail reconnection (Yin and Winske, 2002, and references therein). Effects of the conductivity gradient on the polar cap boundary flow channels are emphasized by Sandholt and Farrugia (2009) and Wang et al. (2010).

Stage 4 is in the dusk cell marked by southeastward convection on the equatorward side of the polar cap boundary in the Harang discontinuity region. This phenomenon we shall refer to as the streamer channel. This stage is also characterized by poleward boundary intensifications (PBIs) in the aurora, which are activated by dynamic plasma sheet processes such as magnetotail reconnection - cross-tail current disruptions (indicated by the dashed line across the mid-tail) - magnetic field dipolarizations - bursty bulk flows (BBFs) (Birn et al., 2011). Dipolarizations/BBFs may give rise to intervals of locally enhanced dawn-dusk directed electric fields $\left(E_{\mathrm{Y}}=V_{\mathrm{X}} B_{\mathrm{Z}}\right)$ of $\sim 2-5 \mathrm{mV} \mathrm{m}^{-1}$ in the few $R_{\mathrm{E}}$ wide sector of the BBFs. The dawn-dusk electric field is enhanced inside the plasma bubble due to electric polarization (Sergeev et al., 1996; Kauristie et al., 2000). The plasma bubbles are flux tubes with depleted density and plasma pressure and containing a double vortex flow pattern (see e.g. Chen and Wolf, 1993, and Kauristie et al., 2000). The convection and FACs are indicated in Fig. 1. The FACs close in the ionosphere through an azimuthal current (yellow) of Type I in Bostrom's categorization (Boström, 1964). This ionospheric current 


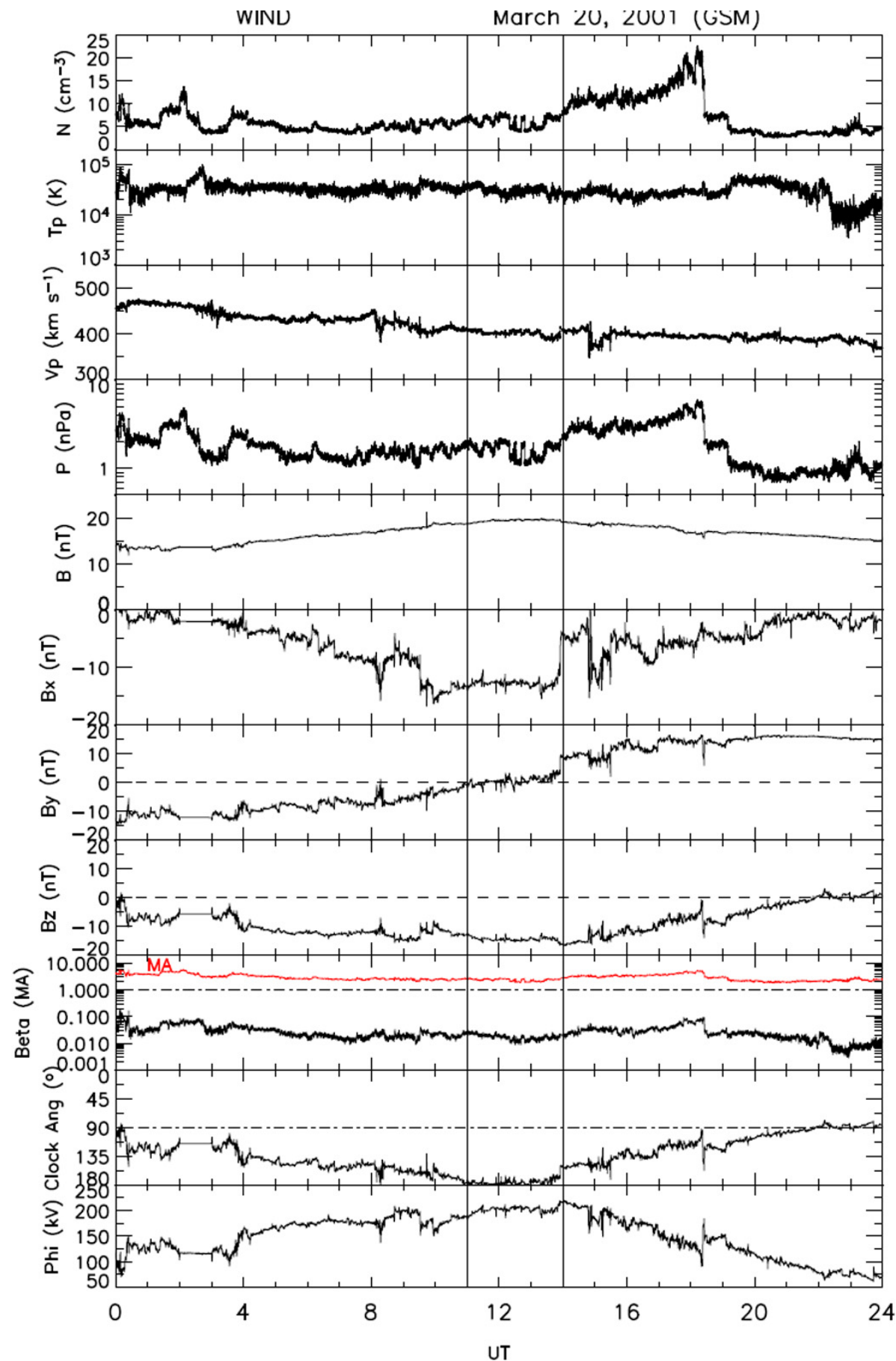

Fig. 2. Solar wind plasma and IMF observations from the spacecraft WIND for 20 March 2001. The panels show, from top to bottom, proton density, proton temperature, bulk speed, solar wind dynamic pressure, the magnetic field strength and GSM components $\left(B_{\mathrm{X}}, B_{\mathrm{y}}\right.$ and $\left.B_{\mathrm{Z}}\right)$ of the interplanetary magnetic field, the proton beta and (in red) the Alfvén Mach number, the IMF clock angle $(\theta)$ and the polar cap potential calculated by the Boyle formula. Transition between three $B_{\mathrm{y}}$ states $\left(B_{\mathrm{y}}<0, B_{\mathrm{y}} \simeq 0, B_{\mathrm{y}}>0\right)$ are marked by vertical lines.

closure gives rise to flow channel FC 4. The upward directed FAC component is accompanied by the phenomenon of auroral streamers (Sergeev et al., 2004). In the case we study we shall document the ground magnetic signature of the FC 4 - auroral streamer system due to the associated Hall currents (see Sandholt et al., 2002).

In the expansion-contraction model of polar cap convection (Siscoe and Huang, 1985; Cowley and Lockwood, 1992) 


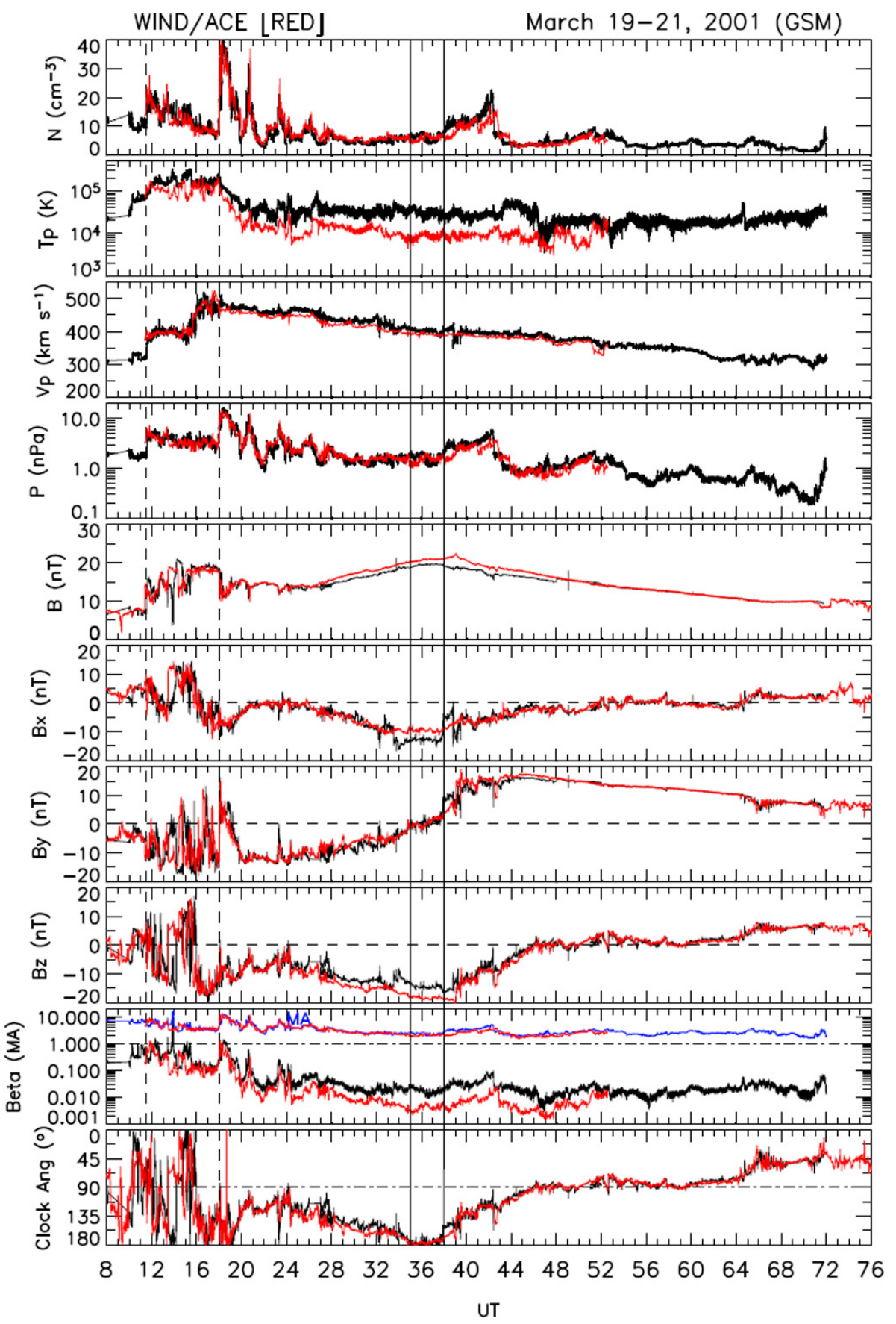

Fig. 3. WIND-ACE data overlay with ACE data shifted one hour.

it is suggested that the CPCP as measured along the 06:0018:00 MLT meridian (by, say, low-altitude spacecraft in polar orbit) consists of a superposition of contributions from the dayside (MP reconnection: flux opening rate) and the nightside (magnetotail reconnection: lobe flux closure rate) (Milan et al., 2007, and Boudouridis et al., 2011). This gives rise to three fundamental types of plasma convection patterns, namely, (i) the unbalanced dayside type, (ii) the unbalanced nightside type, and (iii) the more or less balanced day-night type (Cowley and Lockwood, 1992; Provan et al., 2004).

With the aim of distinguishing between the dayside and nightside sources of polar cap convection as manifested in CPCP and flow channels FC 2 and FC 3 we shall investigate the association between the temporal evolution of the CPCP, obtained from DMSP F13 ion drift data along the dawn-dusk meridian, and the WEJ/streamers as monitored 
by the AL-index and local magnetograms in the dusk sector obtained from the IMAGE chain of magnetometer stations in Svalbard - Scandinavia - Russia. These data are furthermore supplemented with global convection plots obtained by the SuperDARN network of ground radars (Greenwald et al., 1995).

We will here focus on the event on 20 March 2001, but several similar events have been found (see Table 1). The interval selected for this study forms part of an ICME which has been also classified as a magnetic cloud (MC) (Burlaga et al., 1981; Lepping et al., 2003). The $B_{\mathrm{y}}$ and $B_{\mathrm{z}}$ components of the cloud field lie in the ranges $[-10,15]$ and $[-15,-5] \mathrm{nT}$, respectively. Initially, the $B_{\mathrm{y}}$ component of the ICME is negative and increases slowly towards zero. Then an impulsive rise to positive $B_{\mathrm{y}}$ values occurs and it remains positive after that.

\section{Data description}

\subsection{Interplanetary data}

Figure 2 shows WIND data for 20 March 2001. From top to bottom the panels show the proton density, temperature, bulk speed, dynamic pressure, total magnetic field and the $\mathrm{x}$-, $\mathrm{y}$ - and z-components in GSM coordinates, the proton $\beta$ and Alfvén Mach number (in red), the clock angle and finally the cross polar cap potential (CPCP) calculated from the Boyle formula (Boyle et al., 1997). During this time Wind was executing a distant prograde orbit, where its Y-coordinate increased to $-220 R_{\mathrm{E}}$ and its $\mathrm{X}$-coordinate was $\sim 0$. However, comparison with ACE near the L1 point shows exactly the same features (see Fig. 3), consistent with the long coherence lengths of plasma and field parameters in ICMEs compared to those in the normal solar wind (Farrugia et al., 2003, 2005). We shall henceforth use Wind data because of the better data coverage and higher resolution. The delay WINDground is estimated to be $\leq 10 \mathrm{~min}$.

Our main focus here will be on the interval 12:0017:00 UT. This ICME interval shows three consecutive stages characterized by $B_{\mathrm{y}}<0, B_{\mathrm{y}} \sim 0$, and $B_{\mathrm{y}}>0 \mathrm{nT}$, respectively. $B_{\mathrm{Z}}$ is negative throughout.

\subsection{Electrojet deflections: ground magnetometer data}

Figure 4 shows the $\mathrm{X}$-component of the geomagnetic field from IMAGE magnetograms for the interval 13:0017:00 UT. The listed stations and their geomagnetic latitudes are HOR $\left(74.1^{\circ} \mathrm{MLAT}\right)$, BJN $\left(71.4^{\circ} \mathrm{MLAT}\right)$, SOR (67. $3^{\circ}$ MLAT), MAS (66.2 ${ }^{\circ}$ MLAT), SOD (63.9 MLAT), OUJ $\left(61,0^{\circ}\right.$ MLAT), and HAN (58. $7^{\circ}$ MLAT). Local maxima of WEJ intensifications are marked by vertical dashed lines at 14:40, 15:28, and 15:58 UT. Each event onset is followed by poleward expansion and equatorward-moving current structures that are often referred to as streamers (the auroral signature). Different streamers following the three onsets are

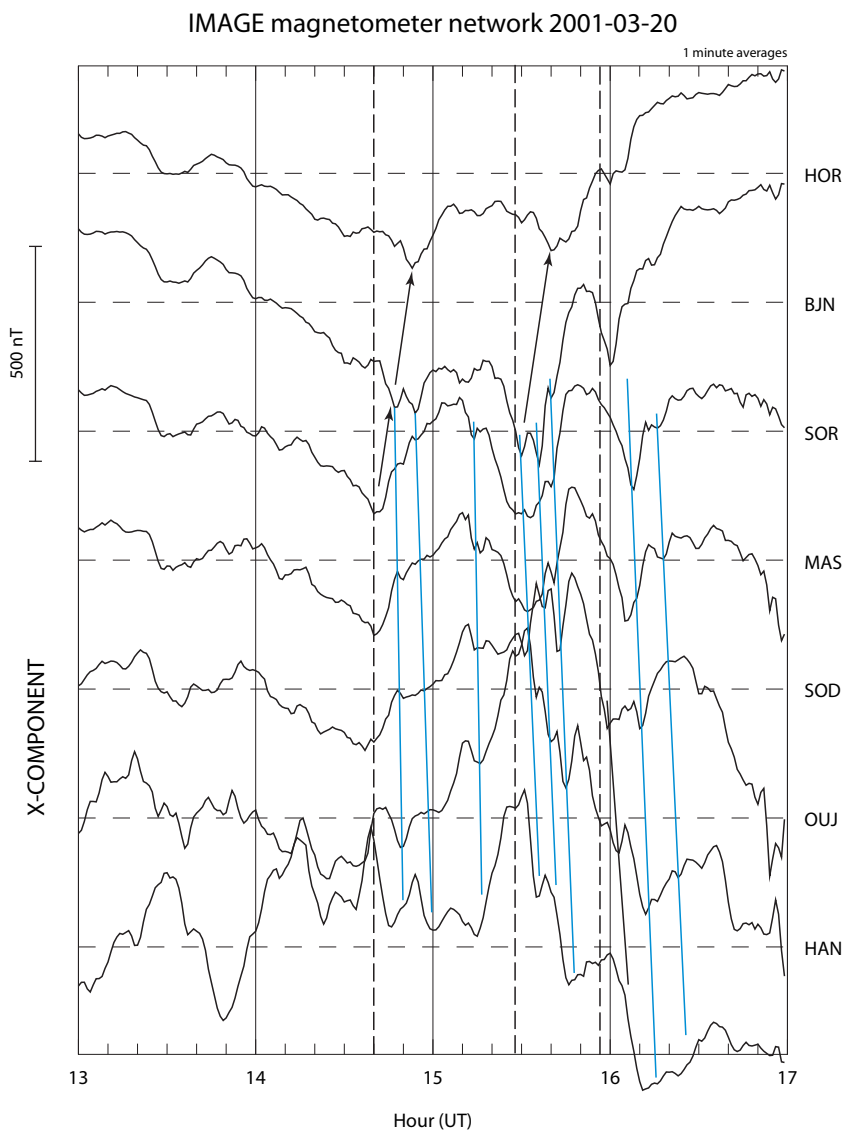

Fig. 4. IMAGE chain magnetometer data for the interval 13:0017:00 UT. Event (WEJ) onsets, poleward expansions, and streamers are marked by vertical dashed lines, arrowed lines, and blue tilted lines, respectively.

marked by blue tilted lines in the figure. The gradual onset of the 14:40 UT WEJ event indicates a westward expansion of this intensification from a source region to the east of our stations. This interpretation is supported by the global UV aurora, as detailed below. Because of the satellite-ground conjunction at 14:40 UT we shall focus on this event. The event onset at station MAS (66.2 MLAT) is followed by a clear poleward expansion, as marked by the successive appearance of negative X-component deflections at the higher-latitude stations SOR $\left(67.3^{\circ} \mathrm{MLAT}\right)$ - BJN $\left(71.1^{\circ} \mathrm{MLAT}\right)$ - HOR (74. $1^{\circ}$ MLAT). The Sym-H, AU and AL indices (Fig. 5) show strong storm and substorm activities. Central to our concerns are the three major AL-deflections occurring in the interval 14:00-15:20 UT. The large negative deflection in the AL index (Tomita et al., 2011) at 14:40 UT coincides with the DMSP pass in the Northern Hemisphere (NH) shown in Fig. 6 and with the electrojet deflection signatures in the IMAGE data. 
Table 1. Interplanetary and Dst conditions for four intervals of ICME passage at Earth.

\begin{tabular}{lccccccccc}
\hline Date & $\begin{array}{c}B_{T} \\
(\mathrm{nT})\end{array}$ & $\begin{array}{c}B_{\mathrm{Z}} \\
(\mathrm{nT})\end{array}$ & $\begin{array}{c}B_{\mathrm{y}} \\
(\mathrm{nT})\end{array}$ & $\theta$ & $\begin{array}{c}V \\
\left(\mathrm{~km} \mathrm{~s}^{-1}\right)\end{array}$ & $\begin{array}{c}n \\
\left(\mathrm{~cm}^{-3}\right)\end{array}$ & $\begin{array}{c}\text { Dst } \\
(\mathrm{nT})\end{array}$ & $\begin{array}{c}E_{\mathrm{KL}} \\
\left(\mathrm{mV} \mathrm{m}^{-1}\right)\end{array}$ & $\begin{array}{c}P_{\text {dyn }} \\
(\mathrm{nPa})\end{array}$ \\
\hline 20 Mar 2001 & 19 & -20 & 0 & $\sim 180^{\circ}$ & 400 & 7 & -149 & 7.6 & $1.1-2.1$ \\
18 Aug 2003 & 17.5 & -14 & -10 & $\sim 150^{\circ}$ & 450 & 2 & -148 & 7.4 & $1-3$ \\
20 Nov 2003 & $40-60$ & $-20-(-50)$ & $40-0$ & $90^{\circ}-180^{\circ}$ & $600-650$ & $8-30$ & -420 & 26.7 & $4-30$ \\
30 May 2005 & 16 & -15 & $-5-(-10)$ & $140^{\circ}-160^{\circ}$ & 450 & 10 & 6.3 & $5-8$ \\
\hline
\end{tabular}

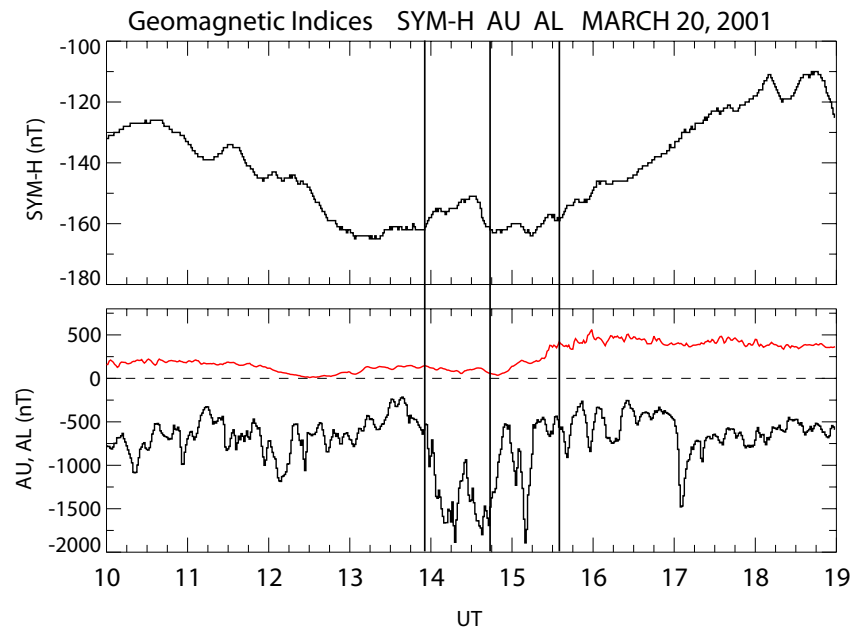

Fig. 5. Sym-H, AU and AL index data. Times of 3 F13 polar cap passes are marked by vertical guidelines.

\subsection{Ionospheric flows and particle precipitation: DMSP data}

Figure 6 shows DMSP F13 data during a NH dusk-dawn pass in the interval 14:30-15:00 UT. From the electron precipitation data in the top panel and the cross-track flow velocities in panel 4 (violet) we may distinguish between a southern auroral branch centered at $60^{\circ}$ MLAT (accompanied by fast sunward convection) and a northern branch (antisunward convection) in the $66^{\circ}-72^{\circ}$ MLAT regime (17:00 MLT). The drift velocity of the antisunward convection in the polar cap (PC) increases from $0.5-1.0 \mathrm{~km} \mathrm{~s}^{-1}$ from the dusk to the dawn-side PC boundary, creating a dawn-dusk asymmetry of the central PC convection as expected for the prevailing IMF $B_{\mathrm{y}}>0$ conditions (after approximately 14:00 UT). A channel of enhanced $\left(>1 \mathrm{~km} \mathrm{~s}^{-1}\right)$ antisunward flow is identified on the dawn side, in the MLAT range $70-75^{\circ}$.

A SH pass during the interval 13:39-14:09 UT is shown in Fig. 7. This time flow channels are present on both the dawn and dusk sides of the polar cap with peak velocities exceeding $2 \mathrm{~km} \mathrm{~s}^{-1}$.

\subsection{Cross polar cap ion drift: DMSP and SuperDARN data}

Figure 8 shows cross-track flows during five consecutive DMSP F13 dawn-dusk passes in the Southern Hemisphere, around the time of the $B_{\mathrm{y}}$ polarity reversal (Fig. 1). Enhanced convection in PC flow channels are marked by blue arrows. We note that these five passes occurred during different stages of magnetic field orientation in the ICME (Fig. 2): (i) $B_{\mathrm{y}}<0$ during the first two passes, (ii) $B_{\mathrm{y}}=0$ during the third and fourth pass, and (iii) $B_{\mathrm{y}}>0$ during the fifth pass. Correspondingly, the PC flows shift from pre-noon to postnoon. So, this figure illustrates the following IMF- $B_{\mathrm{y}}$ dependence pattern of polar cap flow channels in the Southern Hemisphere in this case: (i) flow channel is most prominent on the dawn side in stage 1 (06:00-11:00 UT; $\left.B_{\mathrm{y}}<0\right)$, (ii) is present on both sides in stage 2 (11:00-14:00 UT; $B_{\mathrm{y}}=0$ ), and (iii) is most prominent on the dusk side in stage 3 (14:00 UT onwards; $B_{\mathrm{y}}>0$ ). For the third and fourth passes the dusk side flow channel ocurred at the same time as substorm activity is seen in the AL index (see Fig. 5) at 12:20 and 14:02 UT.

Figures 9 and 10 show the electrostatic potential (in $\mathrm{kV}$ ) along the DMSP F13 tracks for two selected passes, one in the south, centered at 13:54 UT (Fig. 9) and one in the north, centered at 14:44 UT (Fig. 10). The cross-polar cap potential (CPCP) differences are naturally quite high in the south $(158 \mathrm{kV})$ and in the north $(174 \mathrm{kV})$ in view of the very active conditions (the ICME magnetic field). The high CPCP value for the 14:45 UT NH pass is a remarkable feature in this data interval. The 14:45 UT pass is the only one in the north for which the CPCP is higher than the Southern Hemisphere values.

The CPCP values derived for all passes $(\mathrm{SH}$ and $\mathrm{NH})$ in the interval 09:00-17:30 UT are plotted Fig. 11. A clear trend is for the $\mathrm{SH}$ values (red) to be higher than the $\mathrm{NH}$ (blue) values. The 14:45 UT pass in the north highlights a clear exception to this general trend. At this time the $\mathrm{NH}$ value of the CPCP $(174 \mathrm{kV})$ is $30-40 \mathrm{kV}$ higher than for the closest $\mathrm{NH}$ passes.

Figure 12 shows the tracks of the 13:55 UT ( $\mathrm{SH}$; bottom panel) and 14:45 UT (NH; top) F13 passes in MLAT vs. MLT coordinates. The contributions to the CPCP from the flow channels in these cases are indicated in the figure. The 


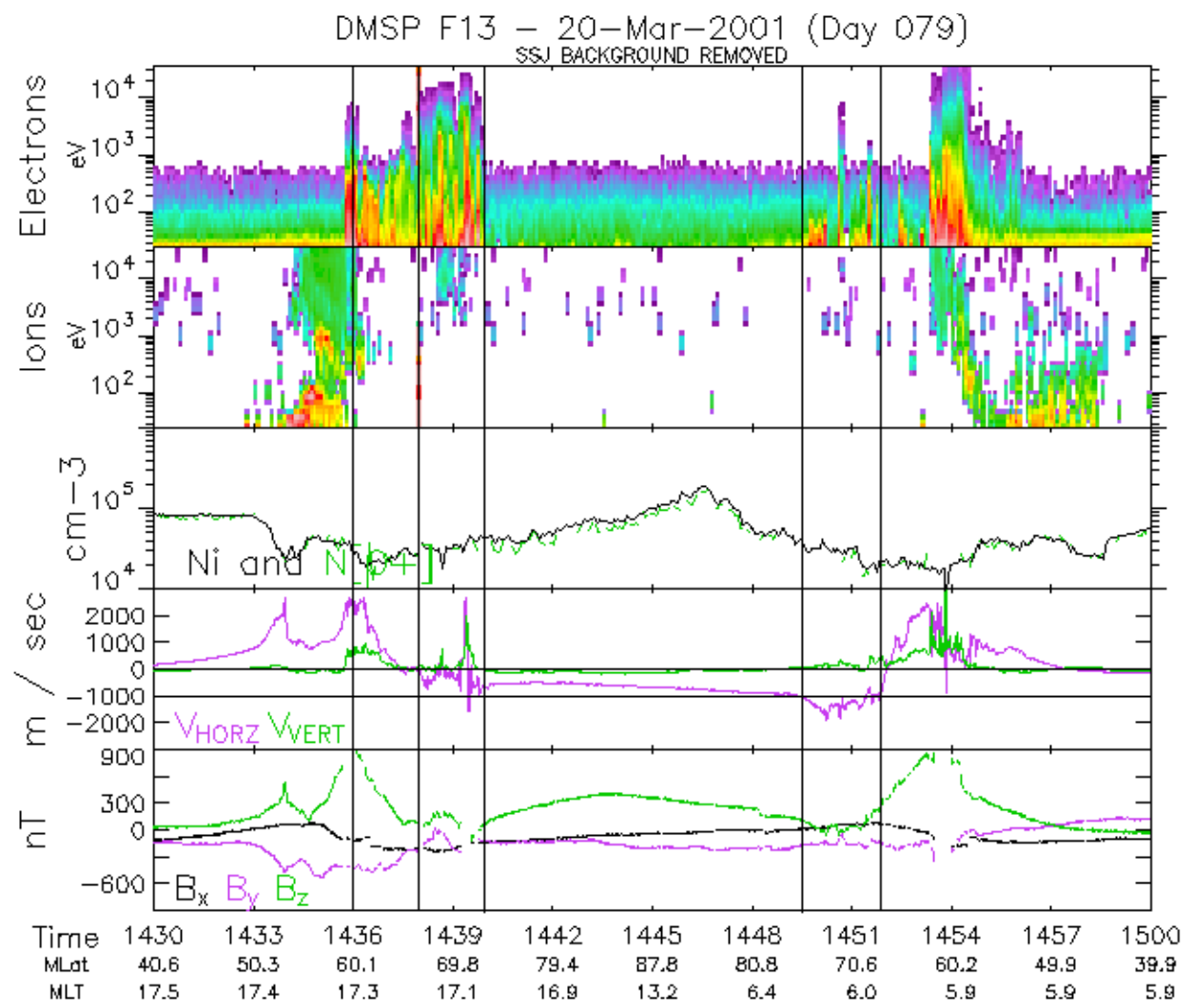

Fig. 6. DMSP F13 data from a dusk-dawn pass 14:30-15:00 UT. Panels from top to bottom show (i) spectrogram of electron and (ii) proton energy fluxes, (iii) ion densities, (iv) cross-track ion drifts (violet), and (v) magnetic deflection components $B_{\mathrm{x}}, B_{\mathrm{y}}$ and $B_{\mathrm{Z}}$. Vertical guidelines mark (i) the most equatorward arc (MEA) at $60 \mathrm{deg}$. MLAT, (ii) the high-latitude auroral branch within 66-72 deg. MLAT, (iii) the polar cap, and (iv) flow channel ( $>1 \mathrm{~km} \mathrm{~s}^{-1}$ antisunward convection) within 70-75 MLAT on the dawn side.

Northern Hemisphere channel traversed at 14:50 UT represented a potential of $50 \mathrm{kV}$ while the two $\mathrm{SH}$ channels at 13:50/14:00 UT contributed 25-30 kV each. The centers of westward (WEJ) and eastward (EEJ) electrojet currents in dusk sector of the Northern Hemisphere at the time of the satellite pass (near 14:40 UT) as derived from magnetograms recorded at the indicated local stations (Fig. 4) have been marked.

A SuperDARN convection plot (in MLT-MLAT coordinates) from the dayside part of the polar cap in Southern Hemisphere at 13:50-13:52 UT is displayed in Fig. 13. Concerning the radar technique we refer to Greenwald et al. (1995) and Ruohoniemi and Baker (1998) (see also Chisham et al., 2007). Two features in the region of good coverage above 70 deg MLAT in the prenoon to dusk sector stand out: (i) a clockwise flow vortex in the post-noon-dusk sector of the polar cap and (ii) relatively homogeneous antisunward convection in the central polar cap. These flow features, including flow channel FC 2 (yellow arrows in 14:0016:00 MLT/70 MLAT sector), are very relevant to our study. This plot, representing the time before the major substorm activity started, resembles a flow pattern one expects for intervals of unbalanced dayside reconnection (see e.g. Provan et al., 2004). We shall return to this topic in the Discussion section.

\subsection{Global UV aurora: IMAGE data}

Here we shall document the central morphological features of the global UV aurora configuration obtained from spacecraft IMAGE (Mende et al., 2000): the presence of double branch oval aurora (Elphinstone et al., 1995) in the 17:00 21:00 MLT sector with auroral streamers extending from the northern branch (characterized by poleward boundary intensifications; PBIs) to the southern branch. This auroral configuration is consistent with the local ground magnetograms indicating streamer activity in the Scandinavian sector (Fig. 4). The previously documented association between auroral streamers and magnetotail bursty bulk flows (BBFs) (see Sergeev et al., 2004) furthermore confirms that BBFs are present in the magnetotail in this interval of ICME passage. We have indicated this in the magnetospheric sketch (Fig. 1).

Six selected UV images illustrating central morphological features of the global UV auroral configuration at six representative times during the interval of interest are shown in Fig. 14: (i) 13:00 UT: expanded polar cap, (ii) 13:59 UT: 


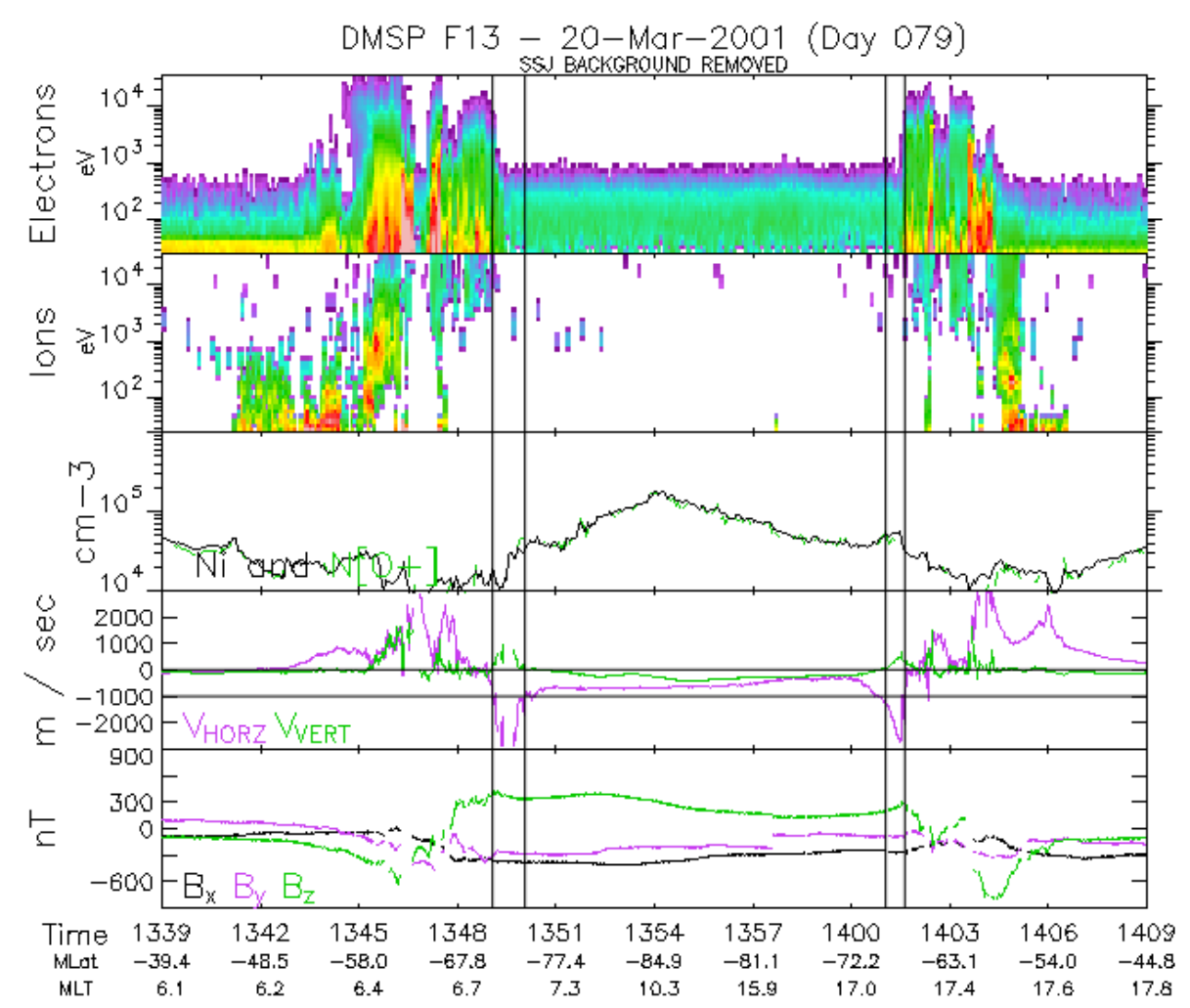

Fig. 7. DMSP F13 data from a dawn-dusk pass in the SH during the interval 13:39-14:09 UT. Same format as in Fig. 6. Vertical guidelines mark flow channels ( $>1 \mathrm{~km} \mathrm{~s}^{-1}$ antisunward convection) on the dawn and dusk sides of the polar cap.

poleward expansion of nighside aurora when the enhanced electrojet activity started, (iii) 14:40 UT: streamer event (north-south oriented aurora) at dusk at the time of local electrojet intensification and DMSP F13 satellite pass, (iv) 14:58-15:43-15:54 UT: the presence of double oval UV aurora (see Elphinstone et al., 1995) in the 17:00-21:00 MLT sector with auroral streamers extending from the northern branch (PBIs) to the southern branch. The local ground magnetic signatures of the auroral streamers in the Scandinavian sector have been marked in Fig. 4. In previous studies we have documented the association between auroral streamers and their ground magnetic signatures (Sandholt et al., 2002).

\section{Summary and discussion}

In this case study we have documented an interesting spatialtemporal structure of polar cap convection during an interval of strong forcing of the magnetosphere when the interplanetary electric field (Kan and Lee, 1979) $E_{\mathrm{KL}}>5 \mathrm{mV} \mathrm{m}^{-1}$ at the time of an ICME passage at Earth. We want to follow the temporal evolution of the CPCP and flow channels appearing at the dawn/dusk sides of the polar cap. We aim at distinguishing between the dayside and nightside sources of these convection phenomena. DMSP ion drift profiles and associated electrostatic potentials across the polar cap were inferred from DMSP F13 data. This information is combined with selected SuperDARN convection plots and ground magnetograms from the Scandinavian sector located at dusk. The latter data in combination with the AL-index are used to monitor the local and global electrojet activities. We are particularly interested in the temporal evolution of polar cap convection associated with the enhanced AL-deflections observed during the interval 14:00-17:00 UT. Global images of the UV aurora from spacecraft IMAGE are used to infer the auroral morphology in the different stages during the interval 13:00-16:00 UT of our case study.

In previous studies we distinguished between two successive stages in the evolution of open field lines within the Dungey convection cycle for southward-directed IMF, i.e. "newly open" (time elapsed since reconnection $<10 \mathrm{~min}$ ) and "old open" (time since reconnection $\sim 10-30 \mathrm{~min}$ ) field lines. Central features of plasma flow in these two stages are the flow channels we refer to as FC 1 (newly open) and FC 2 (old open). Recently two more stages have been added (Fig. 1). While flow channels FC 1 and 2 are driven by dayside reconnection, FC 3 is driven by closure of lobe flux associated with magnetotail reconnection (Fig. 1). In a given hemisphere the flow channel FC 2, characterized by enhanced $\left(>1 \mathrm{~km} \mathrm{~s}^{-1}\right)$ antisunward flow in a restricted latitudinal range at the prenoon/postnoon polar cap boundary, 


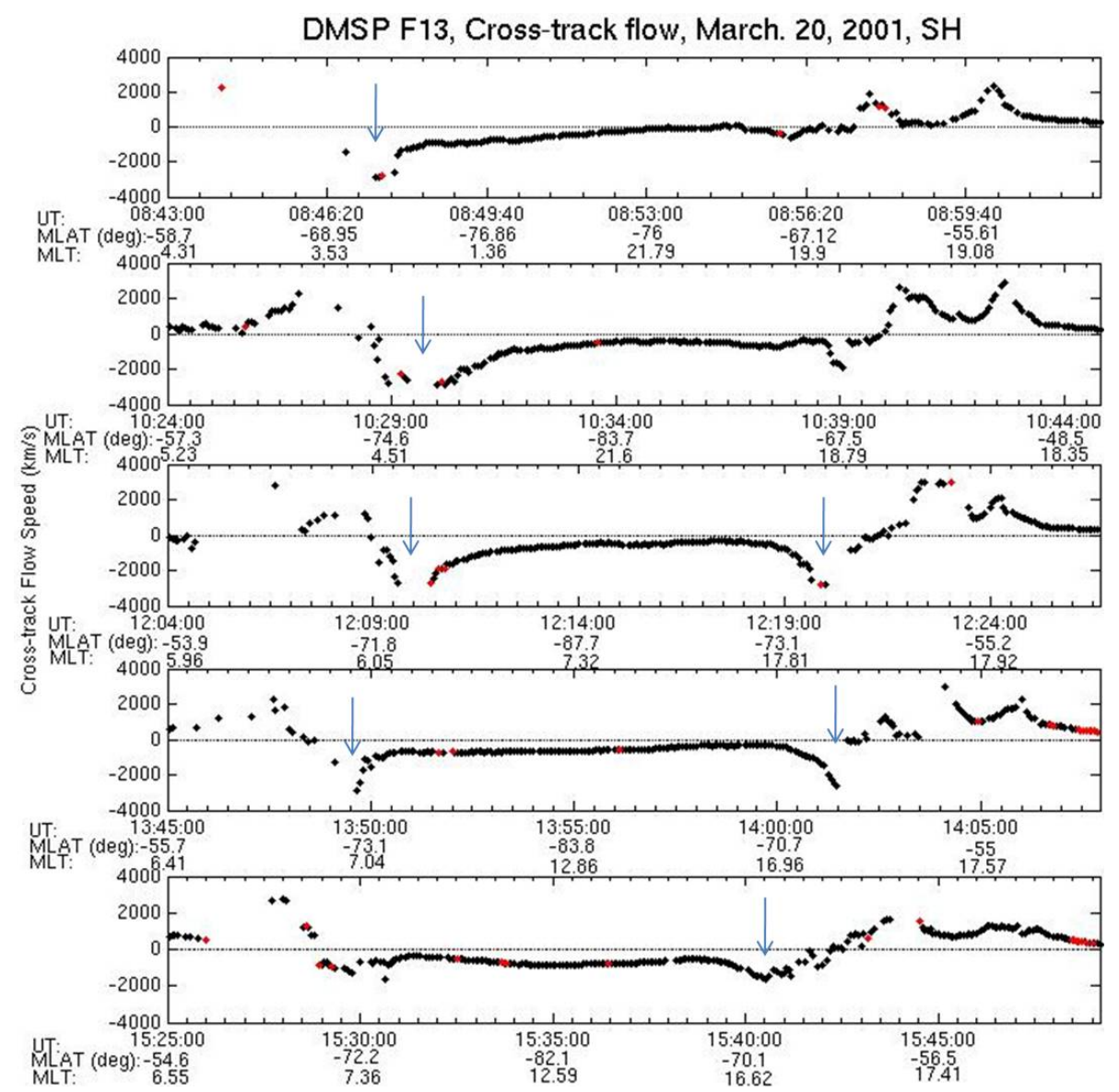

Fig. 8. Cross track flows during five consecutive DMSP F13 dawn-dusk passes in the Southern Hemisphere. Polar cap flow channels on the dawn and/or dusk sides of the PC are marked by blue arrows.

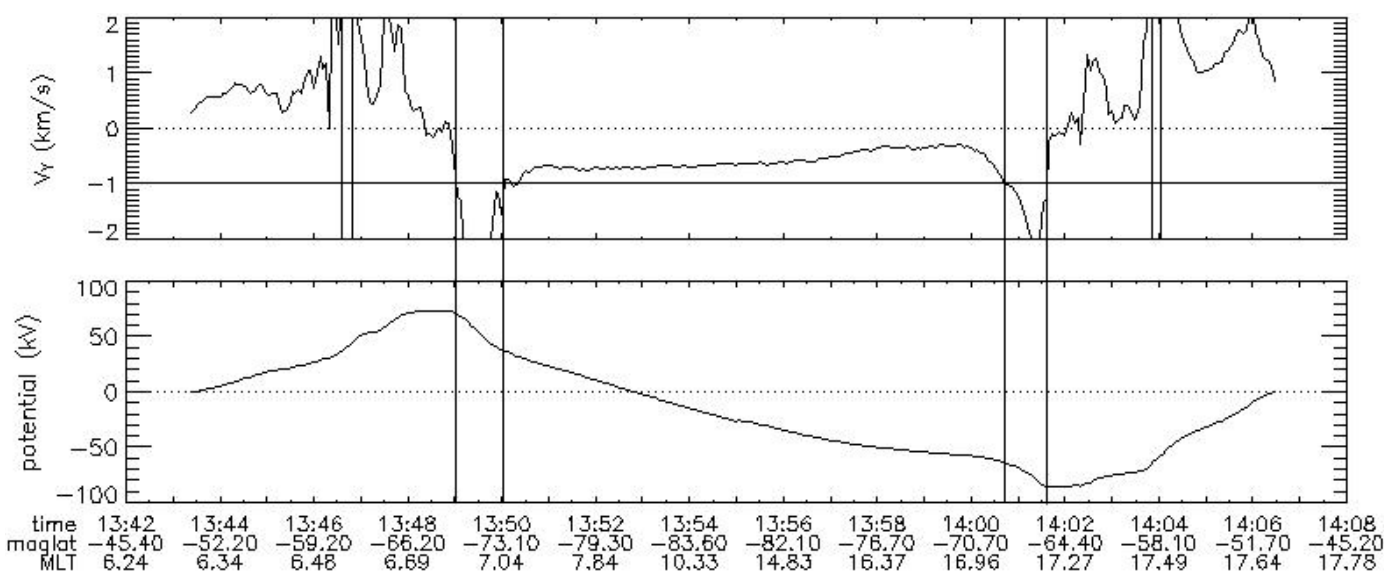

Fig. 9. DMSP F13 pass in the SH for 13:42-14:08 UT. The top panel showing cross track drift and the bottom panel showing electrostatic potential distribution. The vertical lines mark the borders of flow channels to better visualize the potential drop over these channels.

is found at opposite sides of noon corresponding to the two different IMF $B_{\mathrm{y}}$ polarities. Thus, in the case of IMF $B_{\mathrm{y}}$-dominated IMF orientation the FC 2 flow channel contributes to enhancing the IMF $B_{\mathrm{y}}$-related dawn-dusk con- vection asymmetry beyond the cusp region in the antisunward direction. A $B_{\mathrm{y}}$-polarity dependence is confirmed by the present study (see Fig. 8). We here document the presence of flow channels on both the dawn and dusk sides of 


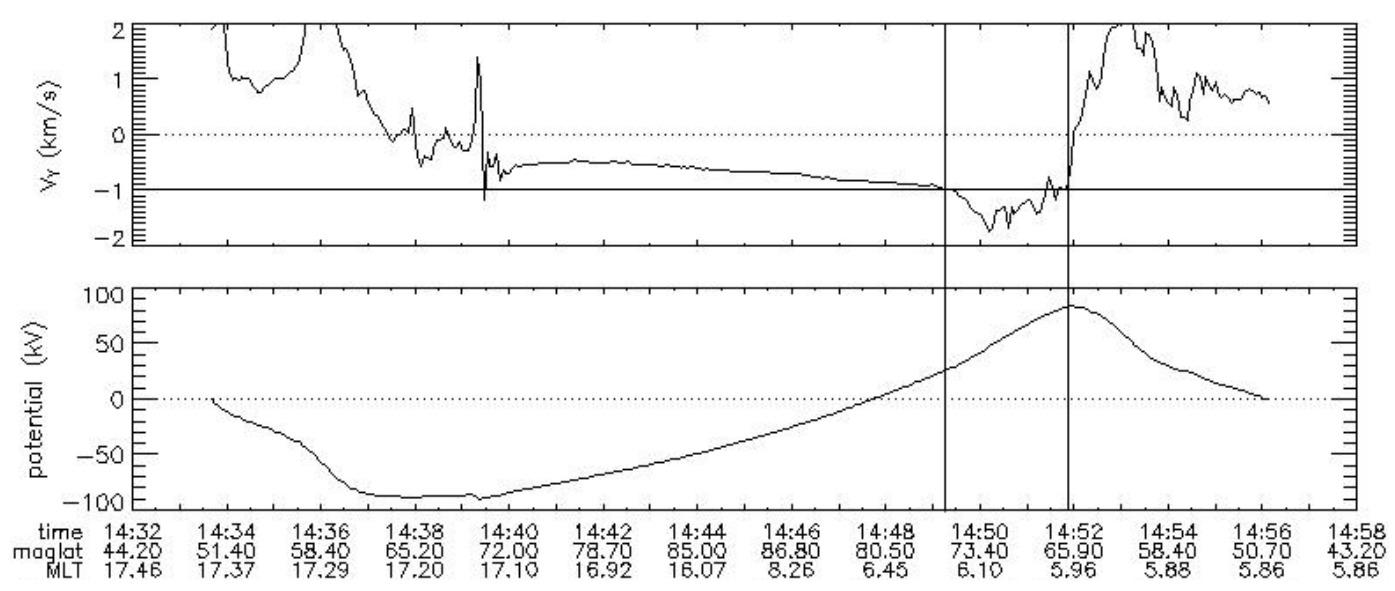

Fig. 10. DMSP F13 pass in the NH for 14:32-14:58 UT. The top panel shows cross track drift and the bottom panel shows the electrostatic potential distribution. The vertical lines mark the borders of a flow channel to better visualize the potential drop over this channel.

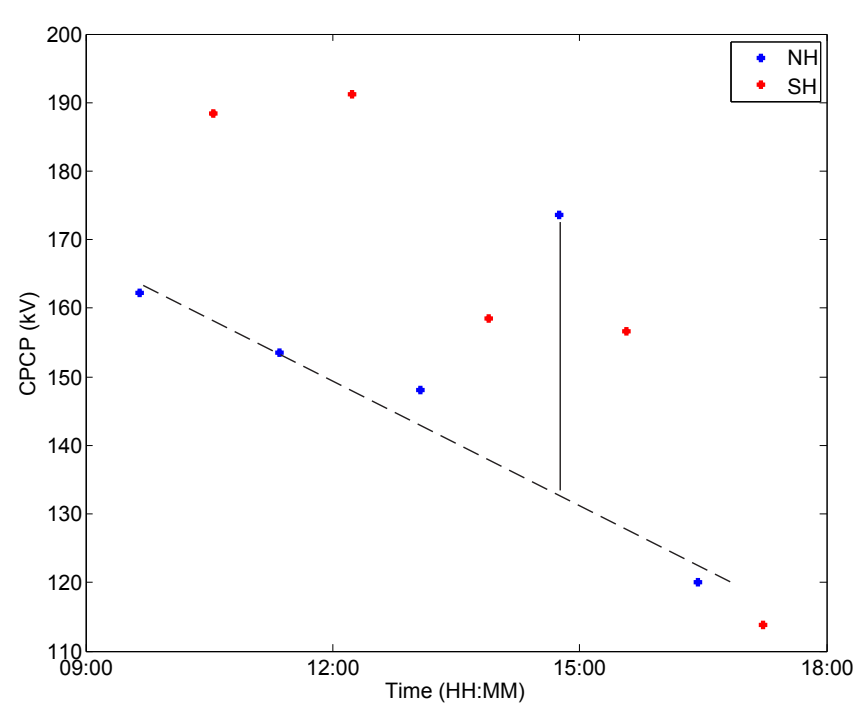

Fig. 11. CPCP estimates for the NH (blue) and $\mathrm{SH}$ (red) obtained from DMSP F13 passes.

the polar cap during the interval 11:00-14:00 UT when the ICME field is $B_{\mathrm{z}}$-dominated ( $B_{\mathrm{y}}=0$ ). This new observation is consistent with the general "rule" that the convection state for $B_{\mathrm{Z}}$-dominated IMF orientation consists of a superposition of $B_{\mathrm{y}}<0$ and $B_{\mathrm{y}}>0$ states.

The two flow channels of the SH DMSP pass centered at 13:55 UT contributed $55 \mathrm{kV}$ to a total CPCP of $158 \mathrm{kV}$, i.e. 35 percent. This is attributed to the magnetopause source, i.e. our flow channel FC 2. This interpretation is supported by the SuperDARN convection plot at 13:50 UT (Fig. 13) which resembles a pattern caused by unbalanced dayside reconnection (see e.g. Provan et al. (2004)). We also note that this DMSP pass occurred just before enhanced substorm activity started (see Fig. 5).
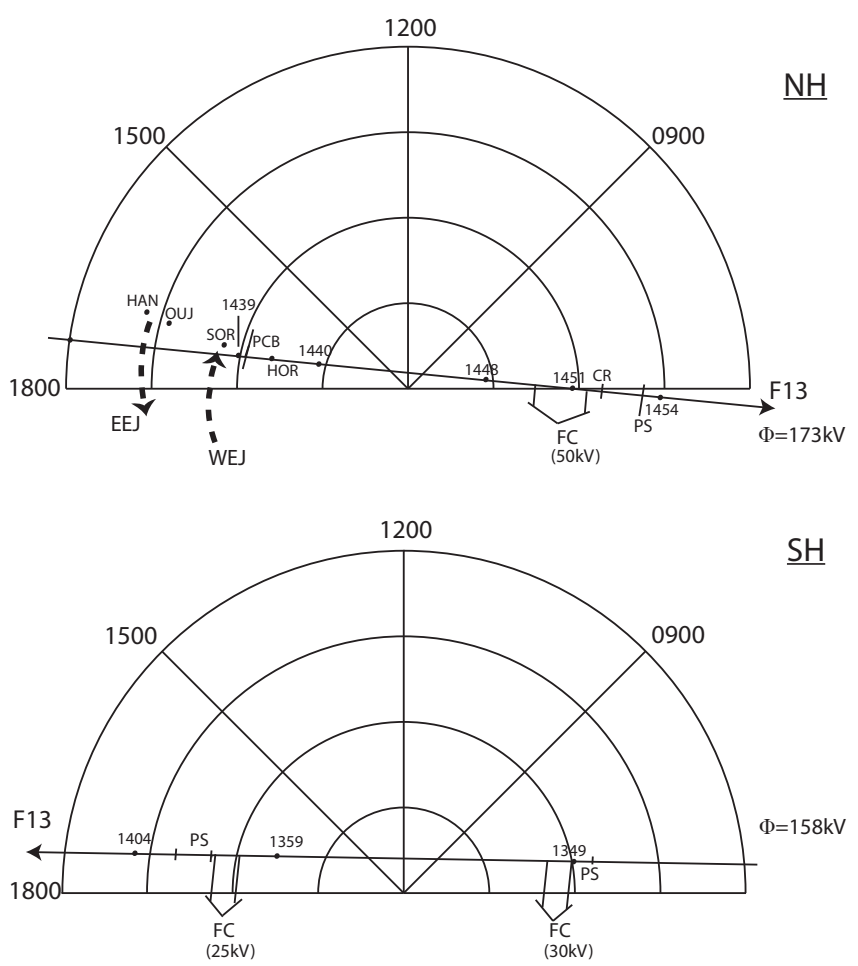

Fig. 12. Sketch of DMSP trajectories in the $\mathrm{SH}$ and $\mathrm{NH}$ in MLAT/MLT coordinates.

We now return to the NH F13 pass centered at 14:45 UT, i.e. in the interval of enhanced substorm activity. A significant increase $(30-40 \mathrm{kV})$ in the CPCP-NH $(173 \mathrm{kV})$ is observed at this time. We hypothesize that this enhancement is due to an active magnetotail source of polar cap convection (see also Provan et al., 2004; Lockwood et al., 2009; Kullen et al., 2010). This interpretation is supported by the local magnetograms in the dusk sector showing a considerable poleward expansion of the westward electrojet in the 


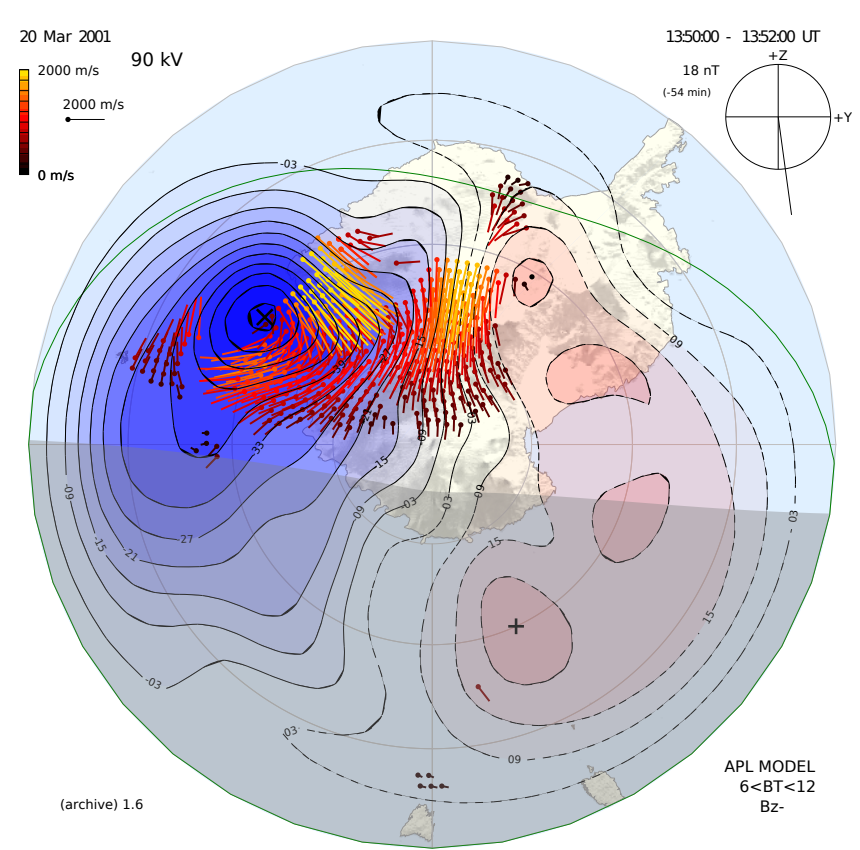

Fig. 13. Southern Hemisphere SuperDARN convection scan for 13:50-13:52 UT. The coordinate system is MLAT/MLT. The Sun is at the top and dusk is to the left.

interval 14:40-14:50 UT (Fig. 4). This is consistent with polar cap contraction and excitation of flow channel FC 3. At this time (14:50 UT) the dawn-side flow channel (FC 3) contributed approximately $50 \mathrm{kV}$ of the CPCP-NH (Fig. 10).

The CPCP is saturated in our case, as is normal when $E_{\mathrm{kl}}>5 \mathrm{mV} \mathrm{m}^{-1}$ (the non-linear regime; see Burke et al. (2007) and references therein). This is demonstrated by the fact that $\Phi_{\text {Boyle }}=200 \mathrm{kV}$ (unsaturated potential), while our CPCP estimates lie in the range $150-190 \mathrm{kV}$. We observe CPCP-SH > CPCP-NH throughout the interval. This interhemispheric asymmetry could be due to conductivity (solar zenith angle) differences in the two hemispheres (see Kan et al., 2010; Peng et al., 2009).

The flow scenario discussed above is consistent with central features of the dynamical changes of the global UV aurora: (1) expanded polar cap before the interval of enhanced substorm activity started at 13:55 UT, and (2) nightside oval contractions (poleward expansions at midnight) accompanied by auroral streamers in the 17:00-21:00 MLT sector in the interval from 13:50 UT onwards.

The previously documented association between auroral streamers and bursty bulk flows (BBFs; see Sergeev et al., 2004) confirms that BBFs are present in association with the substorm activity during this ICME passage which we have marked in the magnetospheric sketch in Fig. 1.

Finally, in Fig. 15 we summarize the essential findings of this study, i.e. the documentation of the association between the following phenomena: (i) WEJ intensifications, followed by poleward expansions, polar cap contractions and auroral
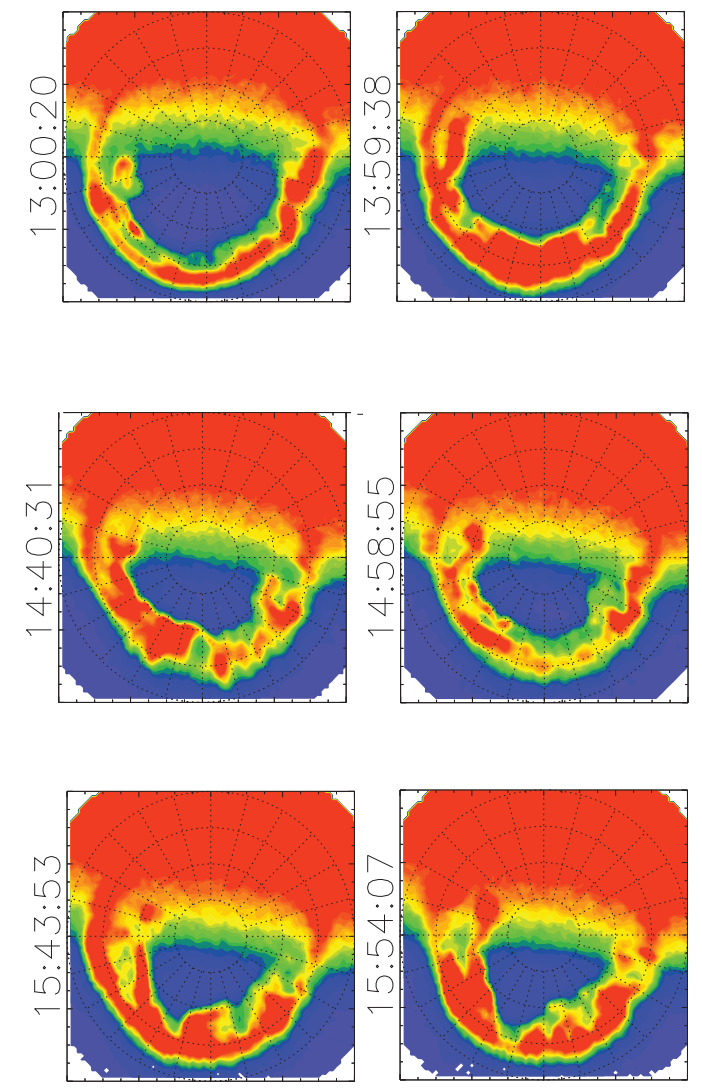

Fig. 14. UV aurora obtained from spacecraft IMAGE.

streamers emanating from the polar cap boundary, as observed in the dusk-premidnight sector, (ii) activation of polar cap flow channel FC 3 (marked in Fig. 15), and (iii) CPCP enhancements as a result of this increased flow.

On the association of streamers - convection - FACs we also refer to Sergeev et al. (2004) and Pitkänen et al. (2011). The convection associated with streamers, which may be referred to as the streamer channel, is marked as stage 4 in Figs. 1 and 15. Polar cap convection jets in the pre-midnight sector (our FC 3 ) have also been reported by Wang et al. (2010). They find that FC 3 occurs in intervals of enhanced $E_{\mathrm{KL}}$.

The dusk side flow channels in the SH DMSP passes at 12:20 and 14:02 UT (Fig. 8) are associated with electrojet intensifications (Fig. 5) and therefore belong to category FC 3. By this data set we have demonstrated the nightside source of polar cap convection in the form of localized flow channels at the dawn/dusk PC boundaries and CPCP enhancements. The implication is that flow channel FC 3 is driven by an enhanced rate of magnetotail reconnection and that this flow channel contributes significantly to the observed CPCP enhancement. This association will be investigated further in future studies.

This study emphasizes the role of magnetotail reconnection for CPCP fluctuations during intervals of strong forcing 


\section{$\mathrm{NH}$-dusk}

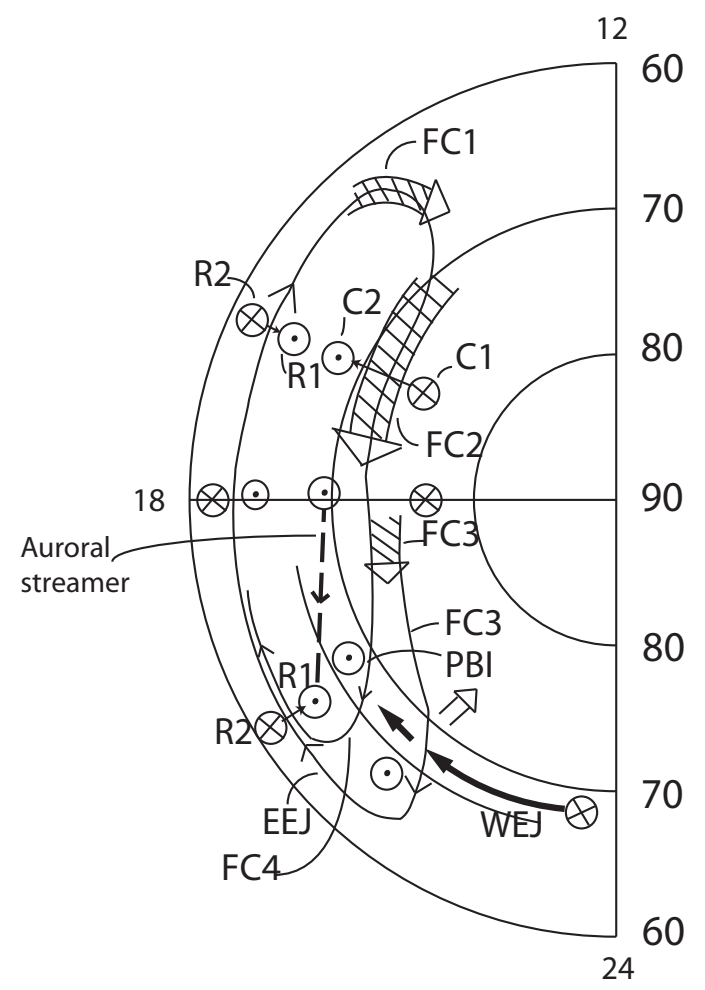

Fig. 15. Schematic illustration of plasma convection, FAC, and electrojet configurations applicable to our case. Flow channels and auroral features (PBI and streamers) in the dusk-premidnight sector are marked. Noon is at the top and dusk is to the left.

of the magnetosphere, when the dayside source had reached a level of saturation. Our scenario of multi-stage/multichannel Dungey cell polar cap convection is placed in the context of substorm activity with auroral streamers and bursty bulk flows.

A comment on the plasma flows in the central polar cap versus that along the periphery may be appropriate at this point. In the center of the polar cap the dayside source of polar cap convection seems to saturate at speeds of 0.8 $1.0 \mathrm{~km} \mathrm{~s}^{-1}$ which is consistent with the results of Troshichev et al. (2000). The moderate speeds of the antisunward convection in the near pole region is contrary to the much higher $\left(1-2 \mathrm{~km} \mathrm{~s}^{-1}\right)$ speeds that are observed along the periphery of the polar cap, on the dawn (NH; $B_{\mathrm{y}}>0$ cases) and dusk (NH; $B_{\mathrm{y}}<0$ cases) sides. The traditional IMF $B_{\mathrm{y}}$-related dawndusk convection asymmetry is often present in the central polar cap (see Fig. 6).

Acknowledgements. Access to the DMSP data base (https://swx. plh.af.mil) was kindly provided by Air Force Geophysics Research Laboratory, Hanscom, Mass through Gordon Wilson. Ground mag- netograms from the Svalbard IMAGE chain of ground stations were obtained from http://www.geo.fmi.fi/image. Thanks to Ari Viljanen and Truls Lynne Hansen for Svalbard magnetograms. We thank M. Ruohoniemi and the SuperDARN team for the convection plots. Thanks to S. E. Milan for providing us with IMAGE UV images (PI: S. B. Mende). Work at University of Oslo is supported by the Norwegian Research Council (NFR). Work at UNH is supported by NASA grant NNX10AQ29G.

Topical Editor I. A. Daglis thanks W. Denig and another anonymous referee for their help in evaluating this paper.

\section{References}

Birn, J., Nakamura, R., Panov, E. V., and Hesse, M.: Bursty bulk flows and dipolarization in MHD simulations of magnetotail reconnection, J. Geophys. Res., 116, A01210, doi:10.1029/2010JA016083, 2011.

Boström, R.: A Model of the Auroral Electrojets, J. Geophys. Res., 69, 4983-4999, doi:10.1029/JZ069i023p04983, 1964.

Boudouridis, A., Lyons, L. R., Zesta, E., Weygand, J. M., Ribeiro, A. J., and Ruohoniemi, J. M.: Statistical study of the effect of solar wind dynamic pressure fronts on the dayside and nightside ionospheric convection, J. Geophys. Res., 116, A10233, doi:10.1029/2011JA016582, 2011.

Boyle, C. B., Reiff, P. H., and Hairston, M. R.: Empirical polar cap potentials, J. Geophys. Res., 102, 111-125, doi:10.1029/96JA01742, 1997.

Burke, W. J., Gentile, L. C., and Huang, C. Y.: Penetration electric fields driving main phase Dst, J. Geophys. Res., 112, A07208, doi:10.1029/2006JA011783, 2007.

Burlaga, L., Sittler, E., Mariani, F., and Schwenn, R.: Magnetic loop behind an interplanetary shock: Voyager, Helios, and IMP8 observations, J. Geophys. Res., 86, 6673-6684, 1981.

Chen, C. X. and Wolf, R. A.: Interpretation of high-speed flows in the plasma sheet, J. Geophys. Res., 98, 21409-21419, doi:10.1029/93JA02080, 1993.

Chisham, G., Lester, M., Milan, S. E., Freeman, M. P., Bristow, W. A., Grocott, A., McWilliams, K. A., Ruohoniemi, J. M., Yeoman, T. K., Dyson, P. L., Greenwald, R. A., Kikuchi, T., Pinnock, M., Rash, J. P. S., Sato, N., Sofko, G. J., Villain, J.P., and Walker, A. D. M.: A decade of the Super Dual Auroral Radar Network (SuperDARN): scientific achievements, new techniques and future directions, Surv. Geophys., 28, 33-109, doi:10.1007/s10712-007-9017-8, 2007.

Cowley, S. W. H. and Lockwood, M.: Excitation and decay of solar wind driven flows in the magnetosphere-ionosphere system, Ann. Geophys., 10, 103-115, 1992.

Dungey, J. W.: Interplanetary Magnetic Field and the Auroral Zones, Phys. Rev. Lett., 6, 47-48, doi:10.1103/PhysRevLett.6.47, 1961.

Elphinstone, R. D., Murphree, J. S., and Hearn, D. J., Cogger, L. L., Sandahl, I., Newell, P. T., Klumpar, D. M., Ohtani, S., Sauvaud, J. A., Potemra, T. A., Mursula, K., Wright, A., and Shapshak, M.: The Double Oval UV Auroral Distribution, 1. Implications for the Mapping of Auroral Arcs, J. Geophys. Res., 100, 1207512092, 1995.

Farrugia, C. J., Matsui, H., and Torbert, R. B.: Coherence Lengths of the interplanetary electric field: Solar Cycle maximum condi- 
tions, SOLAR WIND 10, 679, 766-769, doi:10.1063/1.1618705, 2003.

Farrugia, C. J., Matsui, H., Torbert, R. B., Smith, C. W., Jordanova, V. K., Ogilvie, K. W., Lepping, R. P., Berdichevsky, D. B., Terasawa, T., Kasper, J., Mukai, T., Saito, Y., and Skoug, R.: ICME and Ambient IMF correlations during the Sun-Earth Connection Events of October-November, 2003, J. Geophys. Res., 110, A09S13, doi:10.1029/2004JA010968, 2005.

Greenwald, R. A., Baker, K., Dudeney, J. R., Pinnock, M., Thomas, E. C., Villain, J. P., Cerisier, J.-C., Senior, C., Hanuise, C., Hunsucker, R. D., Sofko, G. J., Koehler, J., Nielsen, E., Pellinen, R., Walker, A. D. M., Sato, N., and Yamagishi, H.: DARN/SuperDARN: A global view of high-latitude convection, Space Sci. Rev., 71, 763-796, 1995.

Kan, J. R. and Lee, L. C.: Energy coupling function and solar windmagnetosphere dynamo, Geophys. Res. Lett., 6, 577-580, 1979.

Kan, J. R., Li, H., Wang, C., Tang, B. B., and Hu, Y. Q.: Saturation of polar cap potential: Nonlinearity in quasisteady SW-M-I coupling, J. Geophys. Res., 115, A08226, doi:10.1029/2009JA014389, 2010.

Kauristie, K., Sergeev, V., Kubyshkina, M., Pulkkinen, T., Angelopoulos, V., Phan, T., Lin, R., and Slavin, J.: Ionospheric current signatures of transient plasma sheet flows, J. Geophys. Res., 105, 10677-10690, doi:10.1029/1999JA900487, 2000.

Kullen, A., Karlsson, T., Cumnock, J. A., and Sundberg., T.: Occurrence and properties of substorms associated with pseudobreakups, J. Geophys. Res., 115, A12310, doi:10.1029/2010JA015866, 2010.

Lepping, R. P., Berdichevsky, D. B., and Wu, C. C.: Sun-Earth electrodynamics: The solar wind connection, Recent Res. Devel. Astrophys., 1, 139-171, 2003.

Lockwood, M., Hairston, M., Finch, I., and Roillard, A.: Transpolar voltage and polar cap flux during the substorm cycle, J. Geophys. Res., 114, A01210, doi:10.1029/2008JA013697, 2009.

Mende, S. B., Heetderks, H., Frey, H. U., Lampton, M., Geller, S. P., Abiad, R., Siegmund, O. W., Tremsin, A. S., Spann, J., Dougani, H., Fuselier, S. A., Magoncelli, A. L., Bumala, M. B., S.Murphree, and Trondsen, T.: Far ultraviolet imaging from the IMAGE spacecraft. 2. Wideband FUV imaging, Space Sci. Rev., 91, 271-285, 2000.

Milan, S. E., Provan, G., and Hubert, B.: Magnetic flux transport in the Dungey cycle: A survey of dayside and nightside reconnection rates, J. Geophys. Res., 112, A01209, doi:10.1029/2006JA011642, 2007.

Papitashvili, V. O., Christiansen, F., and Neubert, T.: A new model of field aligned currents derived from high-precision satellite magnetic field data, Geophys. Res. Lett., 29, A2, doi:10.1029/2001JA900104, 2002.

Peng, Z., Lai, H. R., and Hu, Y. Q.: Transpolar potential and reconnection voltage of the Earth from global MHD simulations, J. Geophys. Res., 114, A04203, doi:10.1029/2008JA013604, 2009.

Pitkänen, T., Aikio, A. T., Amm, O., Kauristie, K., Nilsson, H., and Kaila, K. U.: EISCAT-Cluster observations of quiet-time near-Earth magnetotail fast flows and their signatures in the ionosphere, Ann. Geophys., 29, 299-319, doi:10.5194/angeo29-299-2011, 2011.
Provan, G., Lester, M., Mende, S. B., and Milan, S. E.: Statistical study of high-latitude plasma flow during magnetospheric substorms, Ann. Geophys., 22, 3607-3624, doi:10.5194/angeo-223607-2004, 2004.

Ruohoniemi, J. M. and Baker, K. B.: Large-scale imaging of highlatitude convection with Super Dual Auroral Radar Network HF radar observations, J. Geophys. Res., 103, 20797-20811, 1998.

Sandholt, P. E. and Farrugia, C. J.: Plasma flow channels at the dawn/dusk polar cap boundaries: momentum transfer on old open field lines and the roles of IMF $B_{\mathrm{y}}$ and conductivity gradients, Ann. Geophys., 27, 1527-1554, doi:10.5194/angeo-271527-2009, 2009.

Sandholt, P. E., Farrugia, C. J., Lester, M., Cowley, S., Milan, S., Denig, W. F., Lybekk, B., Trondsen, E., and Vorobjev, V.: Multistage substorm expansion: Auroral dynamics in relation to plasma sheet particle injection, precipitation, and plasma convection, J. Geophys. Res., 107, A11, doi:10.1029/2001JA900116, 2002.

Sandholt, P. E., Andalsvik, Y., and Farrugia, C. J.: Polar cap convection/precipitation states during Earth passage of two ICMEs at solar minimum, Ann. Geophys., 28, 1023-1042, doi:10.5194/angeo-28-1023-2010, 2010.

Sergeev, V., Angelopoulos, V., Gosling, J., Cattell, C., and Russell, C.: Detection of localized, plasma-depleted flux tubes or bubbles in the midtail plasma sheet, J. Geophys. Res., 101, 10817-10826, doi:10.1029/96JA00460, 1996.

Sergeev, V. A., Liou, K., Newell, P. T., Ohtani, S.-I., Hairston, M. R., and Rich, F.: Auroral streamers: characteristics of associated precipitation,convection and field-aligned currents, Ann. Geophys., 22, 537-548, doi:10.5194/angeo-22-537-2004, 2004.

Siscoe, G. and Huang, T.: Polar Cap Inflation and Deflation, J. Geophys. Res., 90, 543-547, doi:10.1029/JA090iA01p00543, 1985.

Southwood, D.: The Ionospheric Signature of Flux Transfer Events, J. Geophys. Res., 92, 3207-3213, 1987.

Tomita, S., Nosé, M., Iyemori, T., Toh, H., Takeda, M., Matzka, J., Bjornsson, G., Saemundsson, T., Janzhura, A., Troshichev, O., and Schwarz, G.: Magnetic local time dependence of geomagnetic disturbances contributing to the AU and AL indices, Ann. Geophys., 29, 673-678, doi:10.5194/angeo-29-673-2011, 2011.

Troshichev, O. A., Lukianova, R. Y., Papitashvili, V. O., Rich, F. J., and Rasmussen, O.: Polar cap index (PC) as a proxy for ionospheric electric field in the near-pole region, Geophys. Res. Lett., 27, 23, doi:10.1029/2000GL003756, 2000.

Wang, H., Lühr, H., and Ridley, A. J.: Plasma convection jets near the poleward boundary of the nightside auroral oval and their relation to Pedersen conductivity gradients, Ann. Geophys., 28, 969-976, doi:10.5194/angeo-28-969-2010, 2010.

Yin, L. and Winske, D.: Simulations of current sheet thinning and reconnection, J. Geophys. Res., 2002, 1485, doi:10.1029/2002JA009507, 2002. 